\title{
Librarians Never Retire!
}

by Lynn Pryor
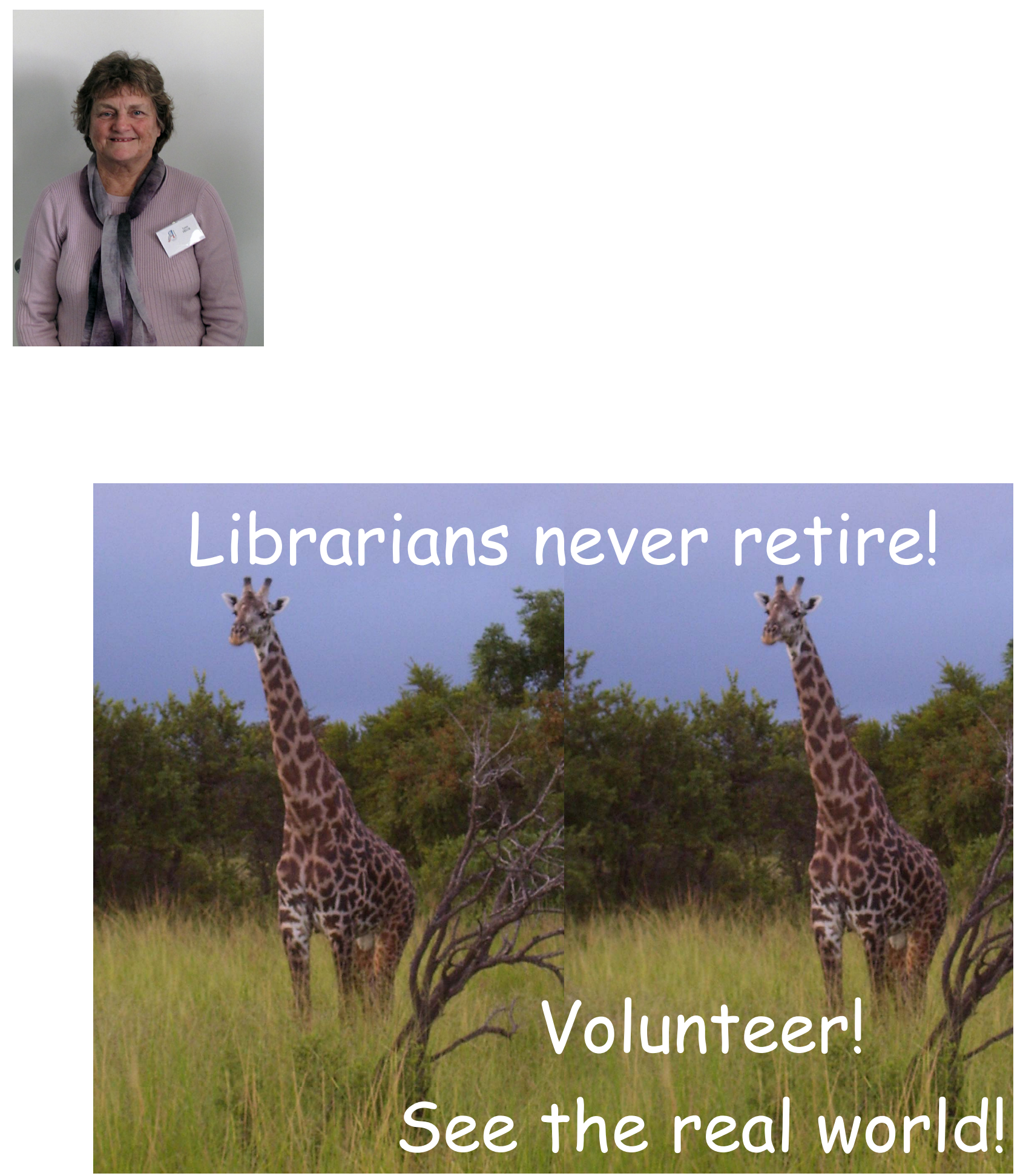

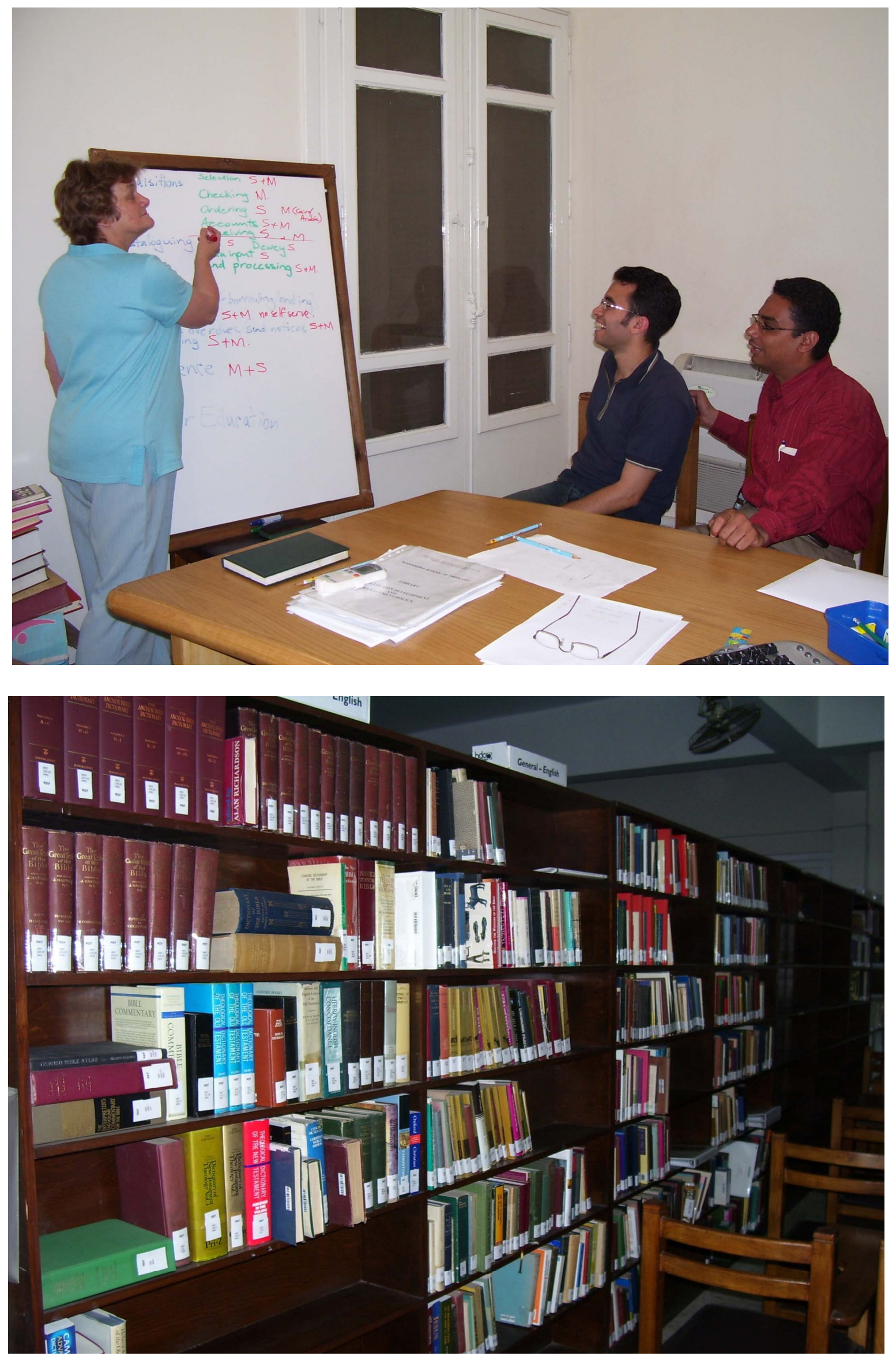

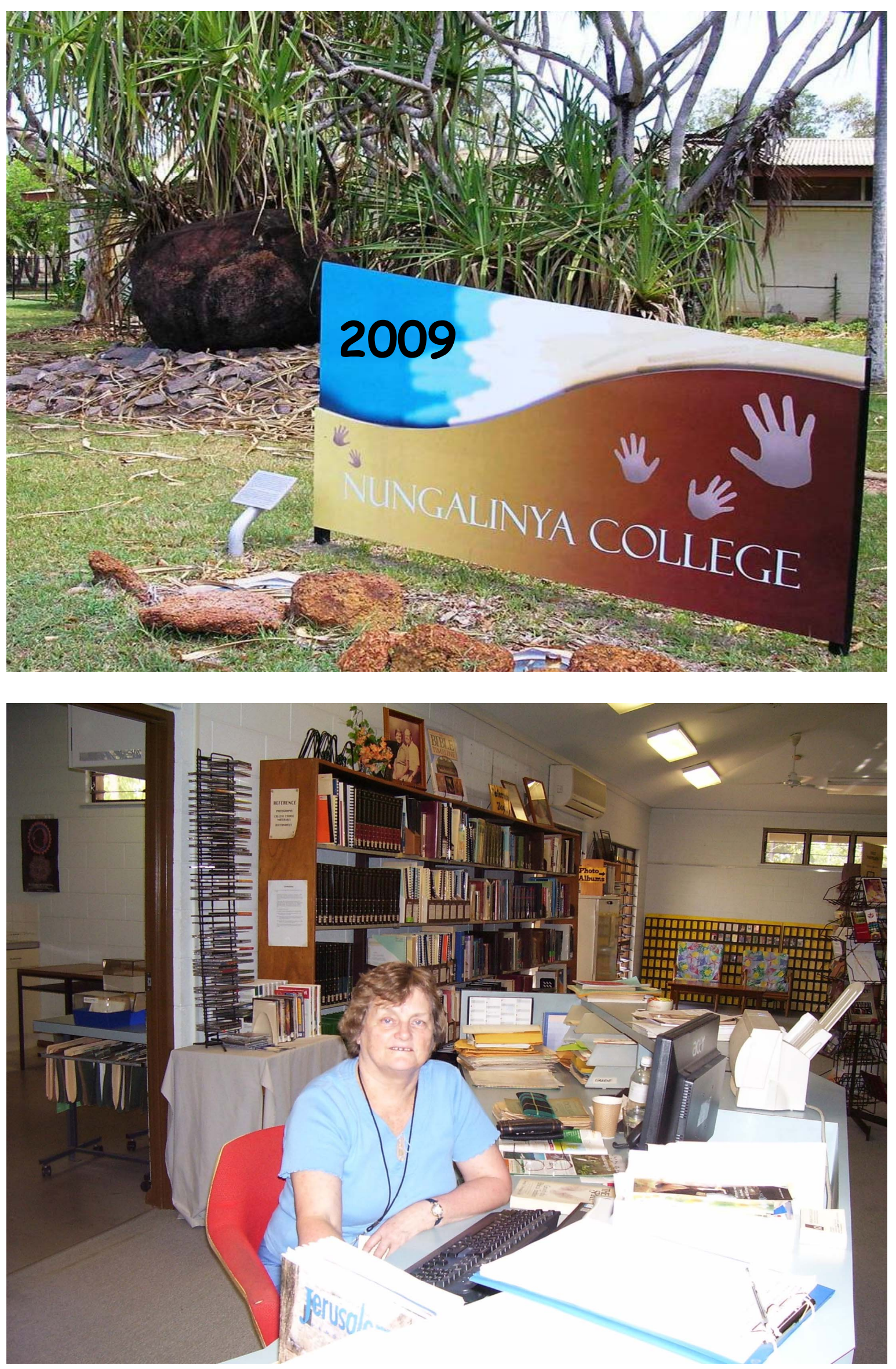


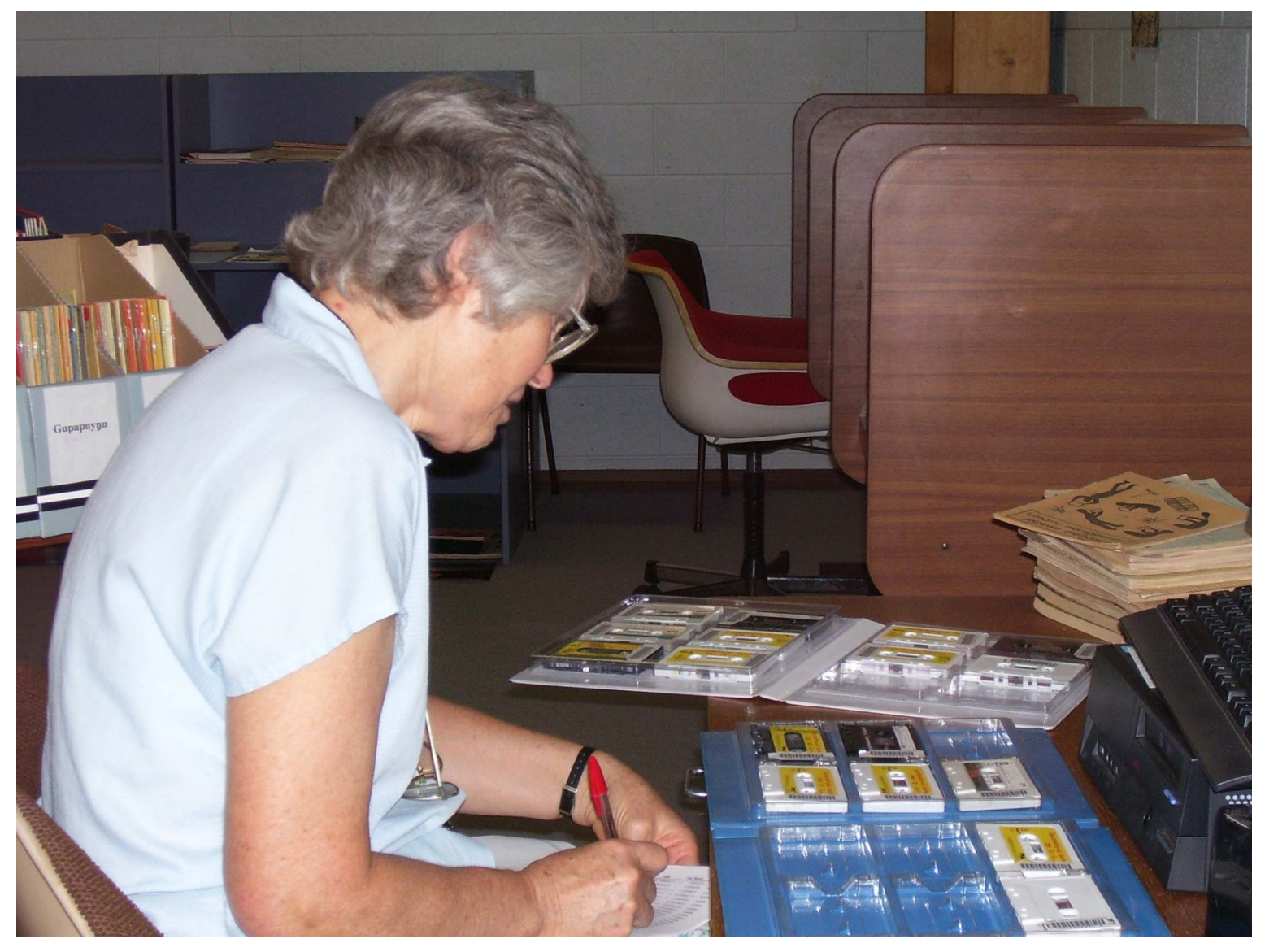

\section{St John's University of Tanzania 2010}

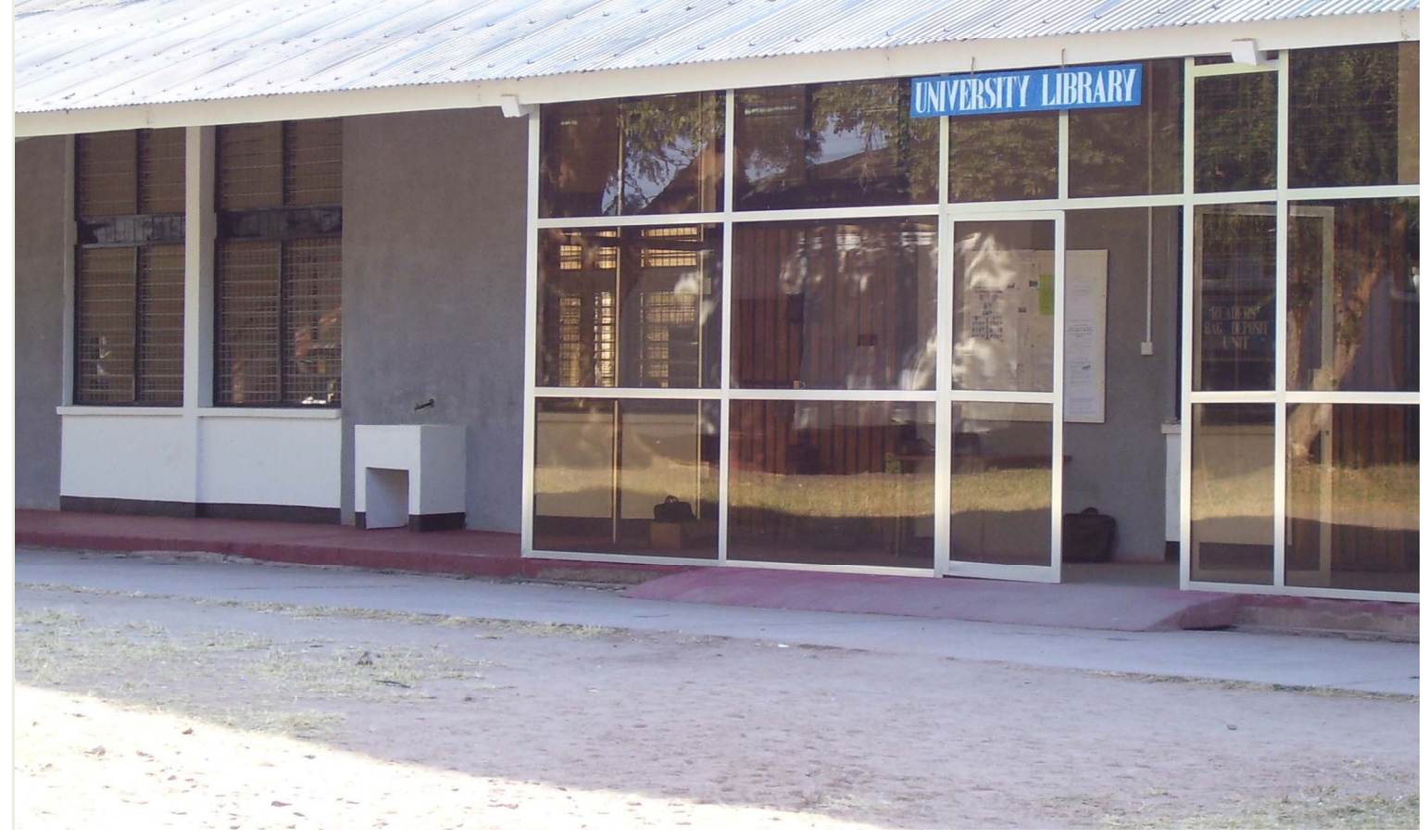



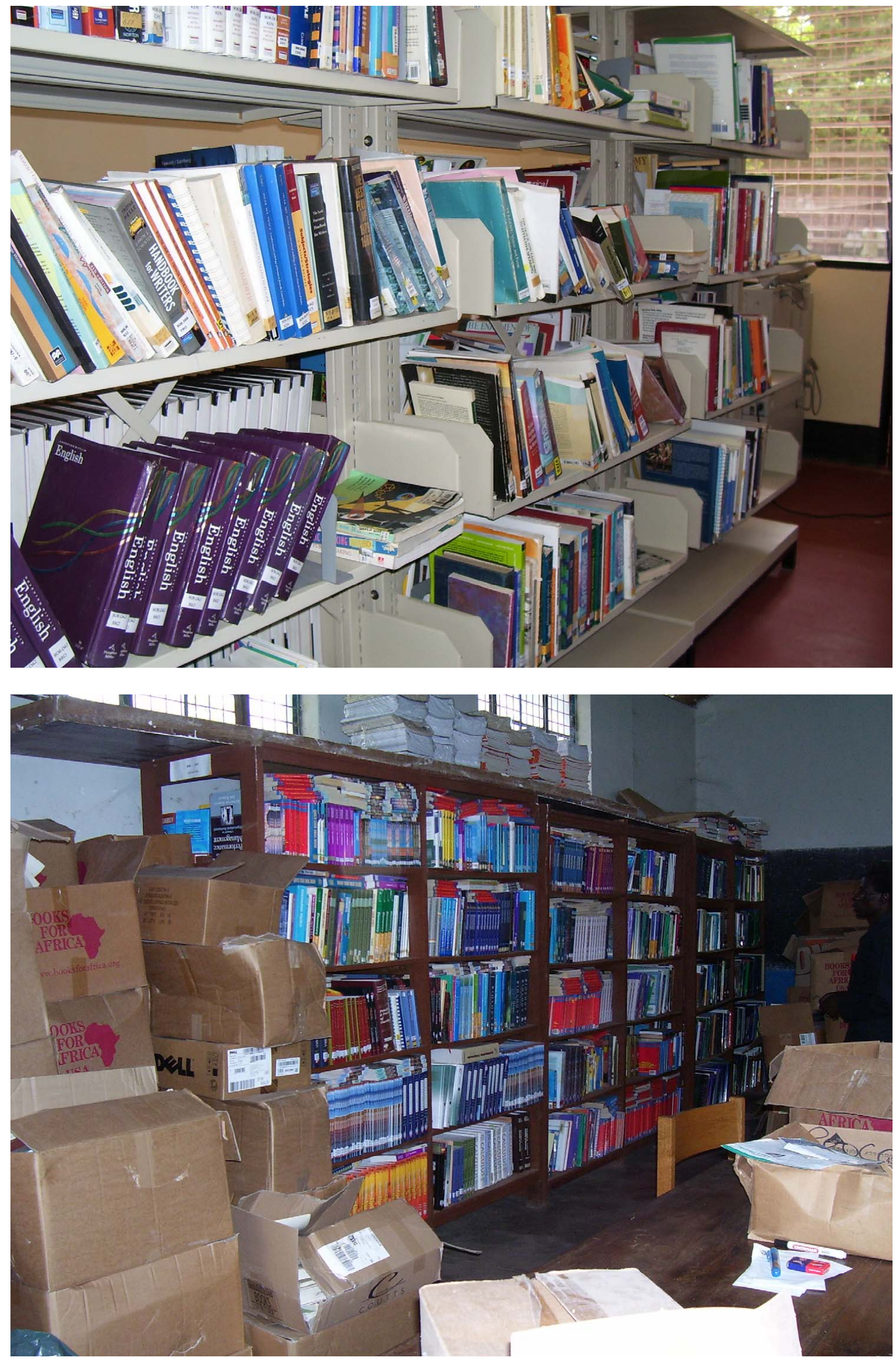

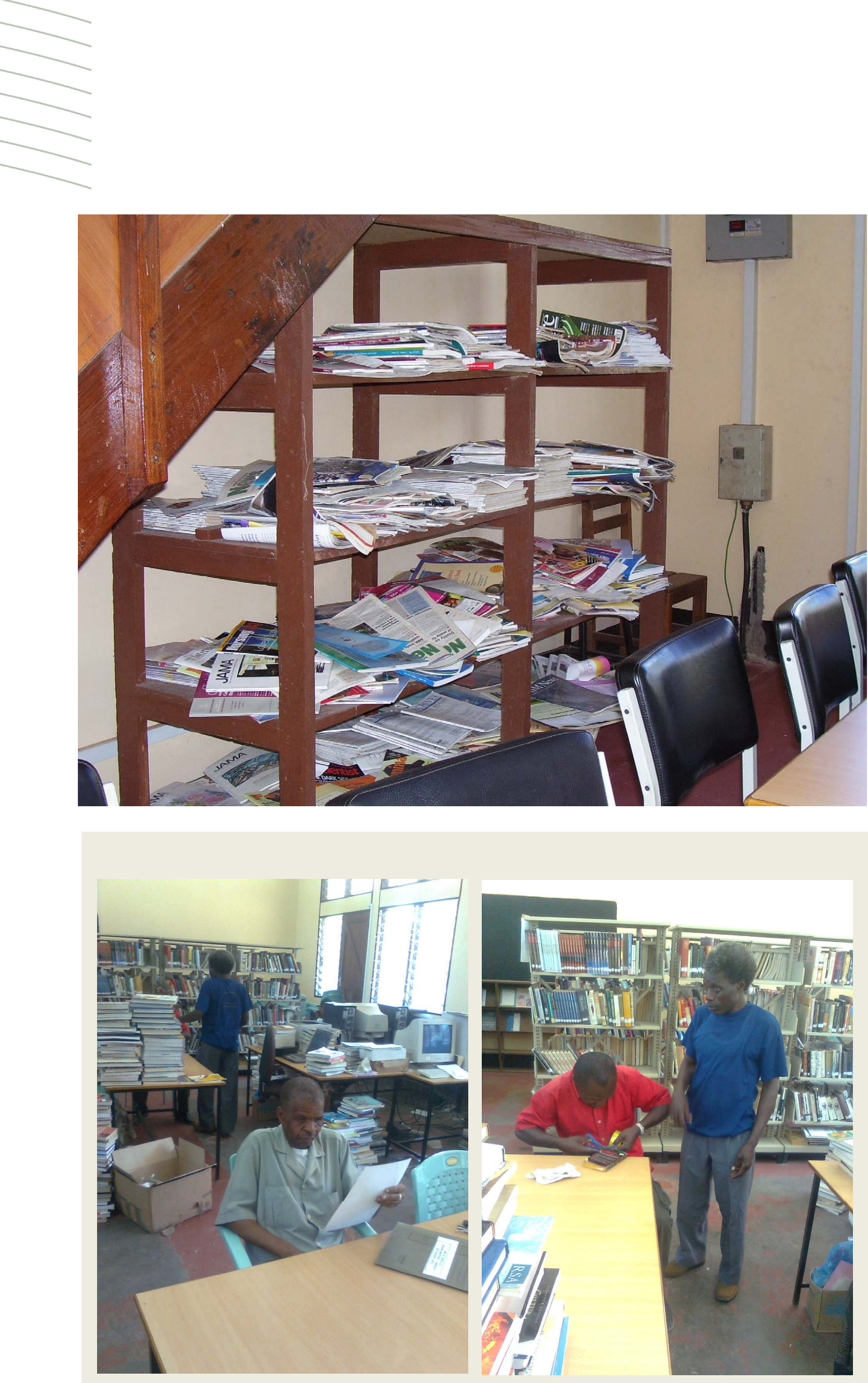

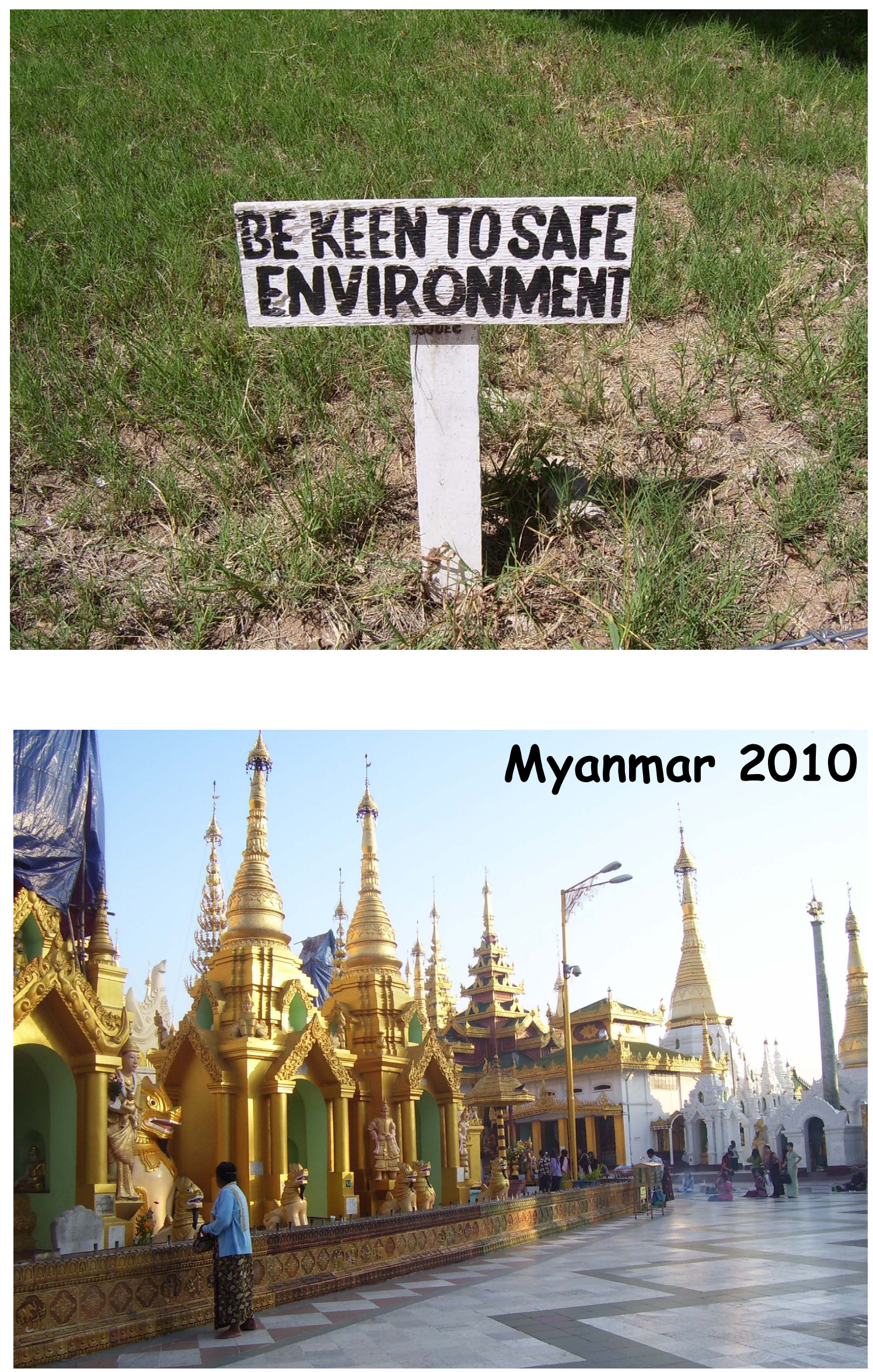

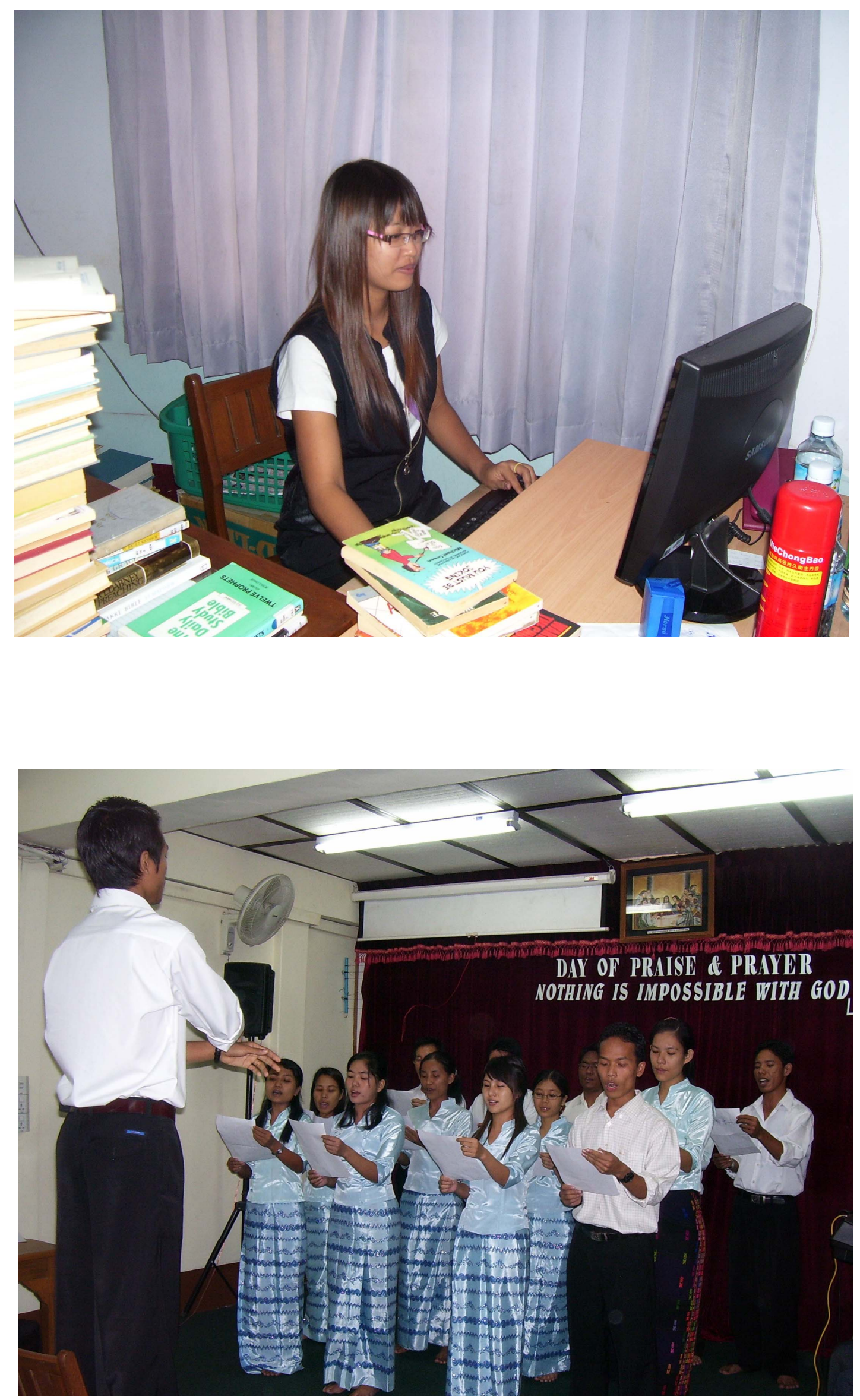

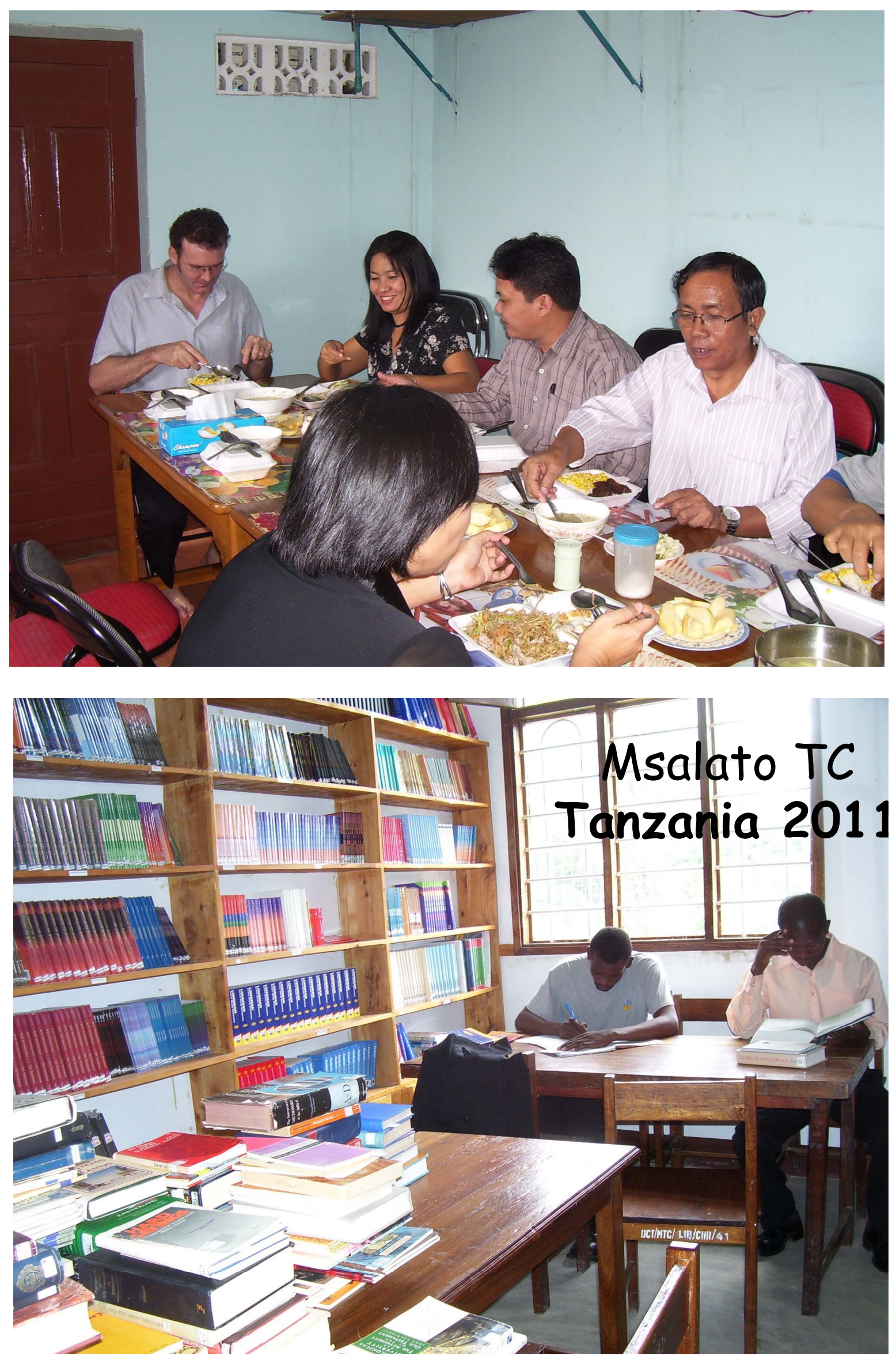

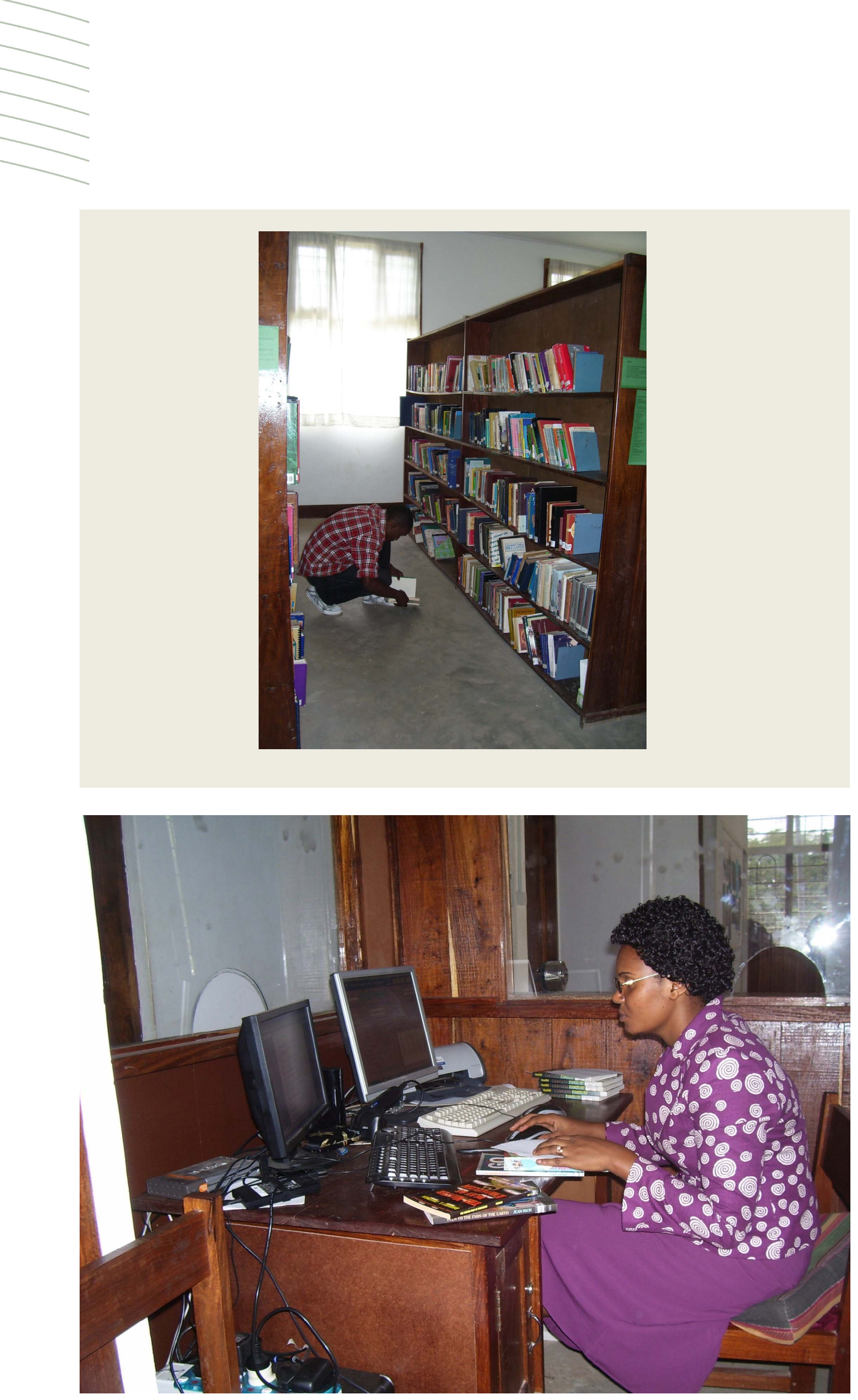

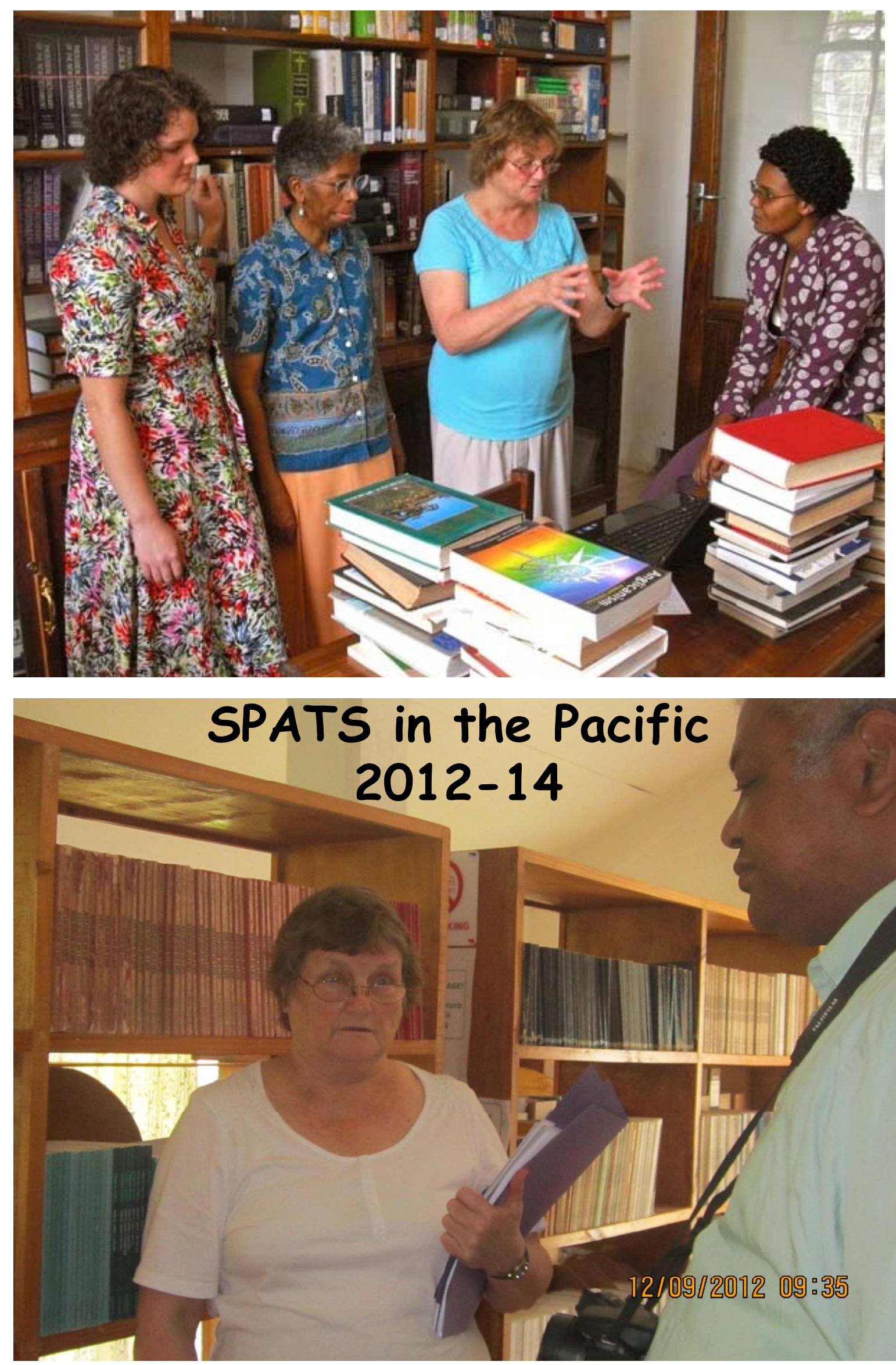

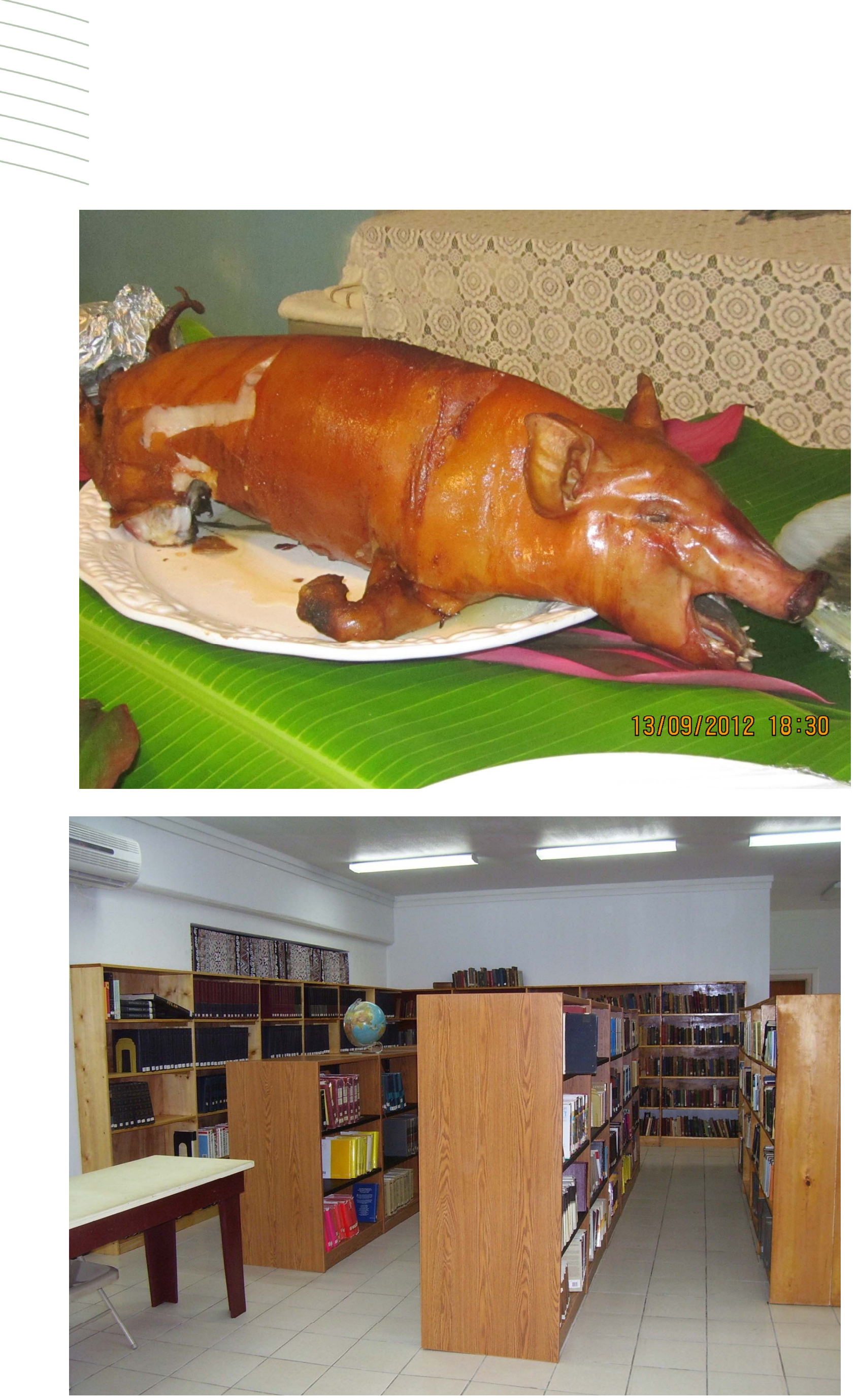


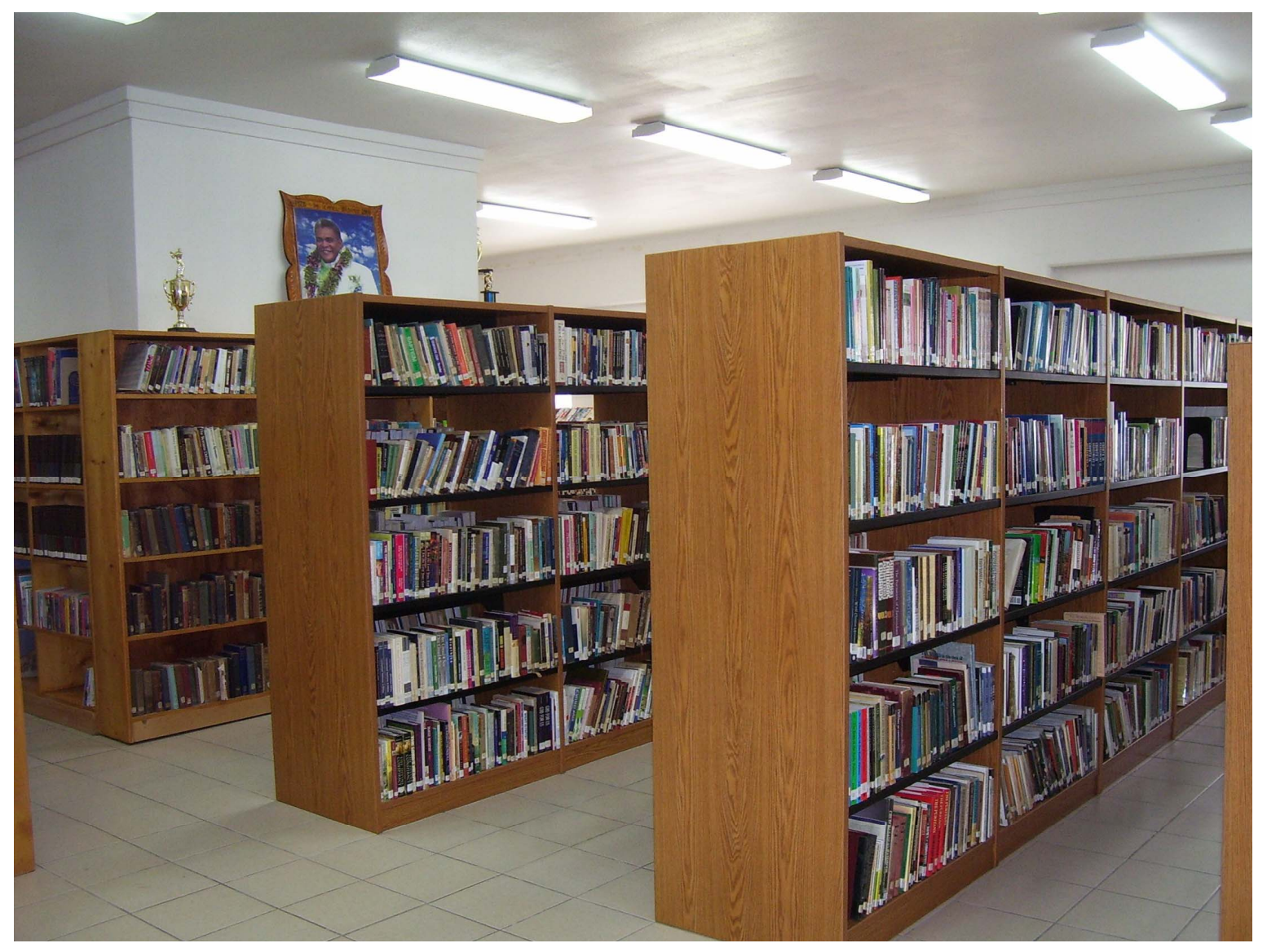

\section{Kathy's adventures}
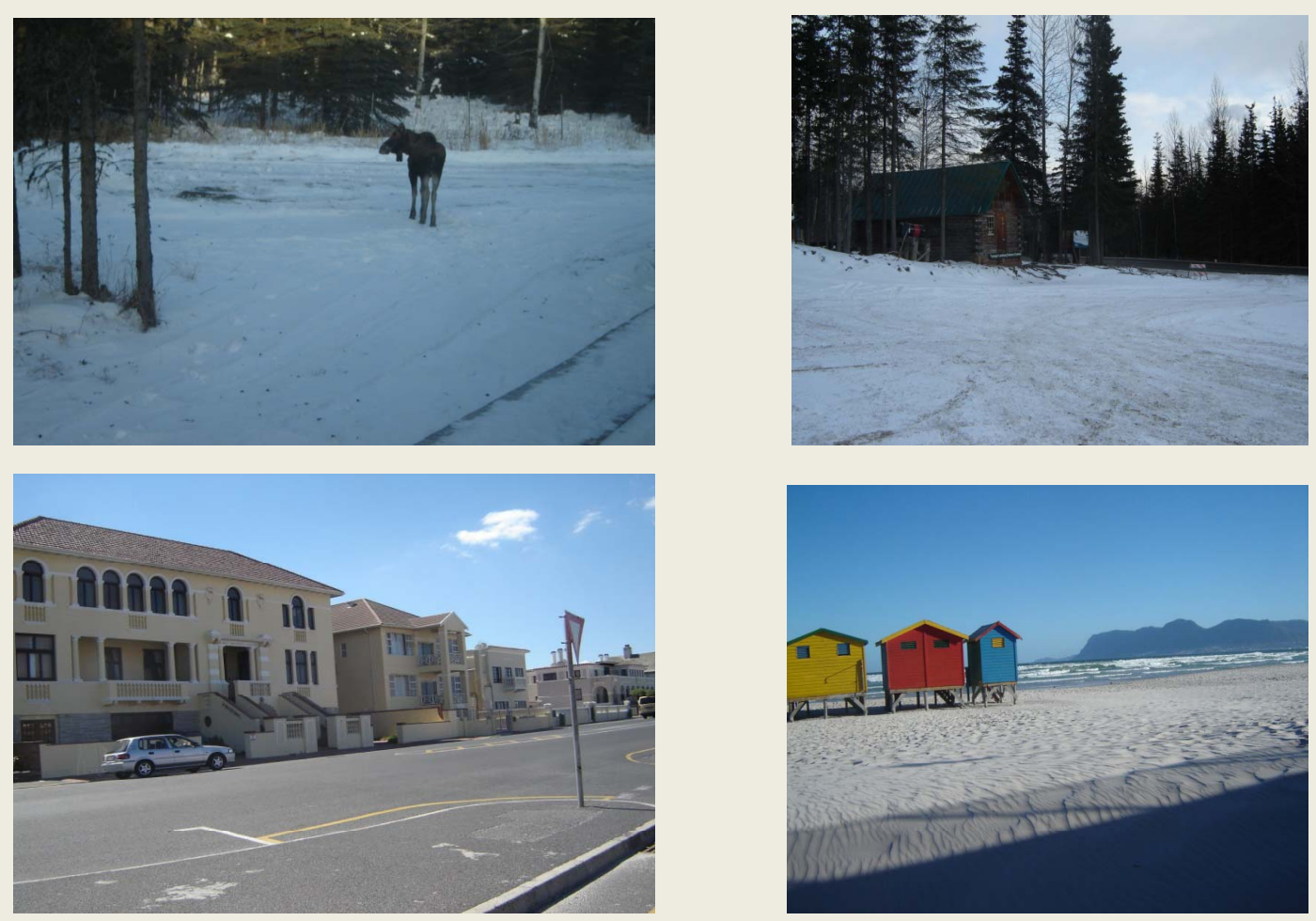

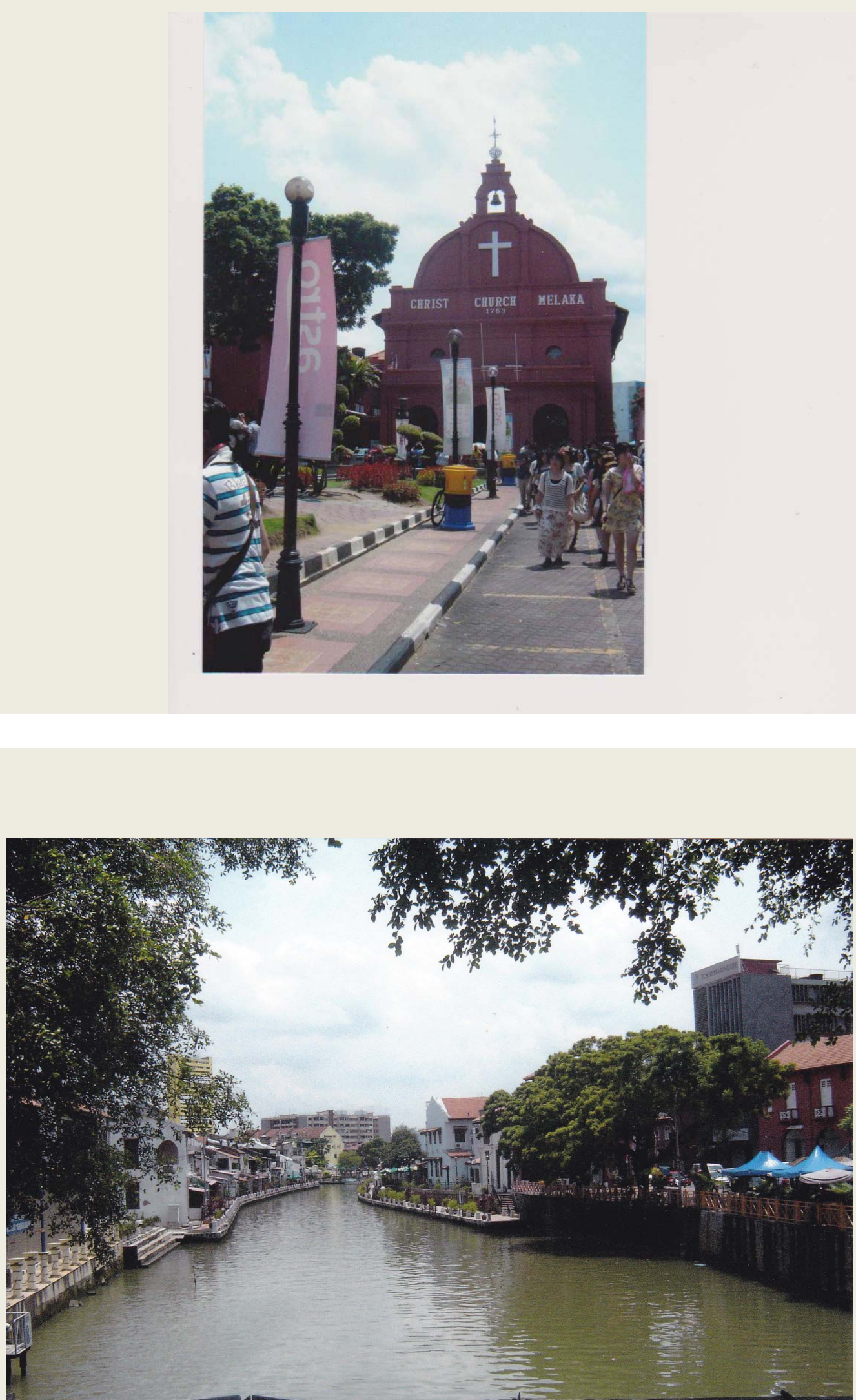

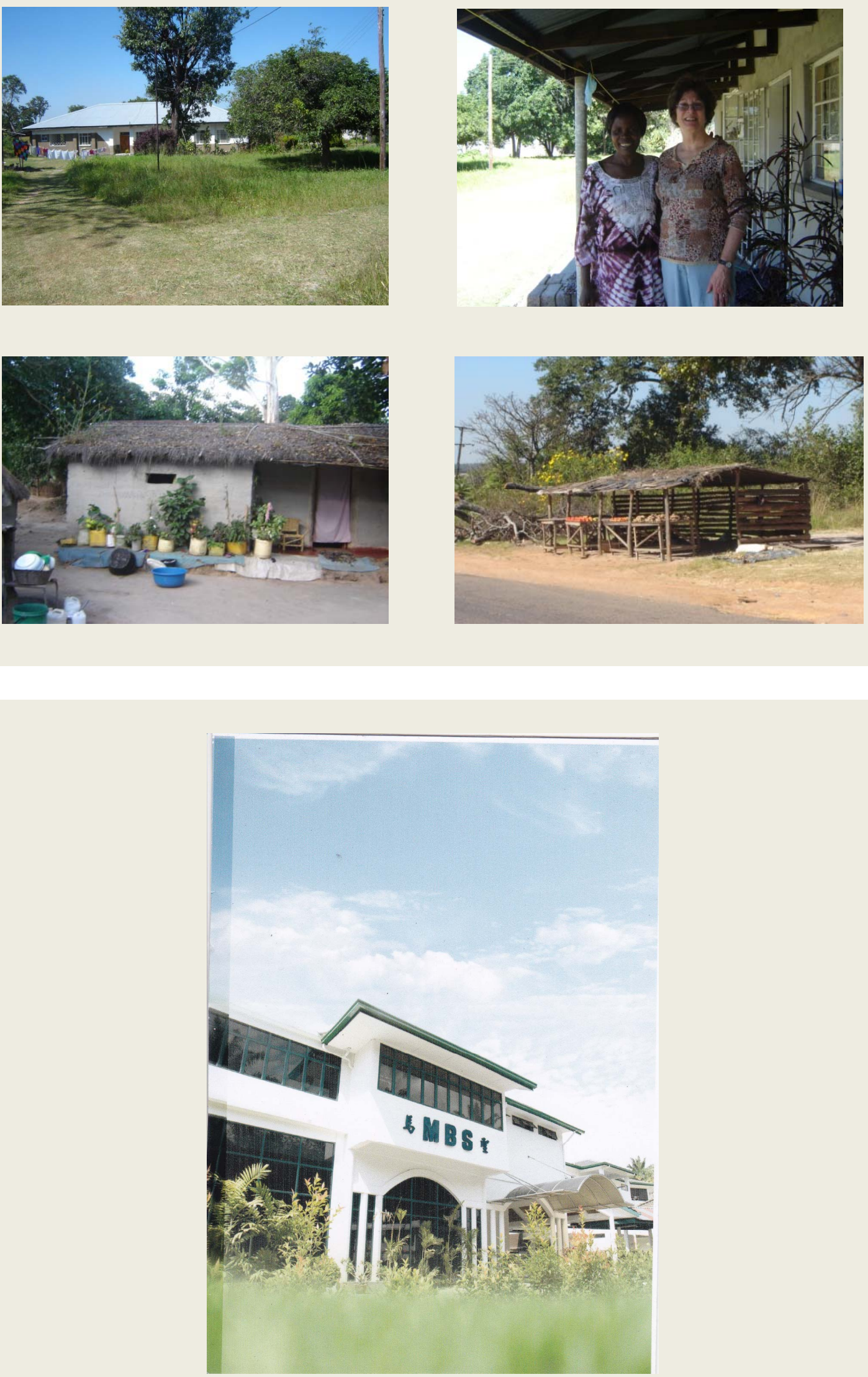


\section{Hans in Myanmar}
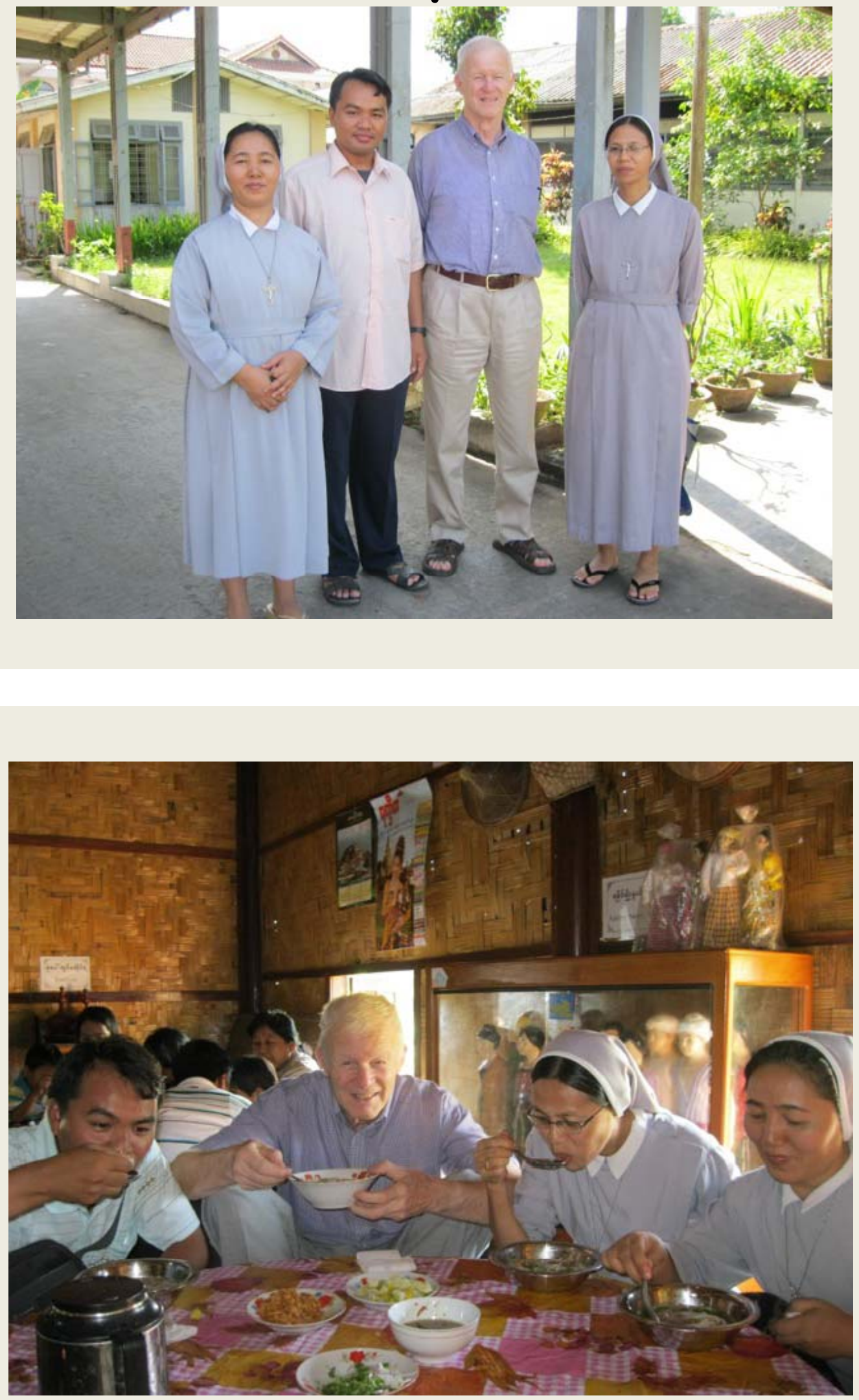


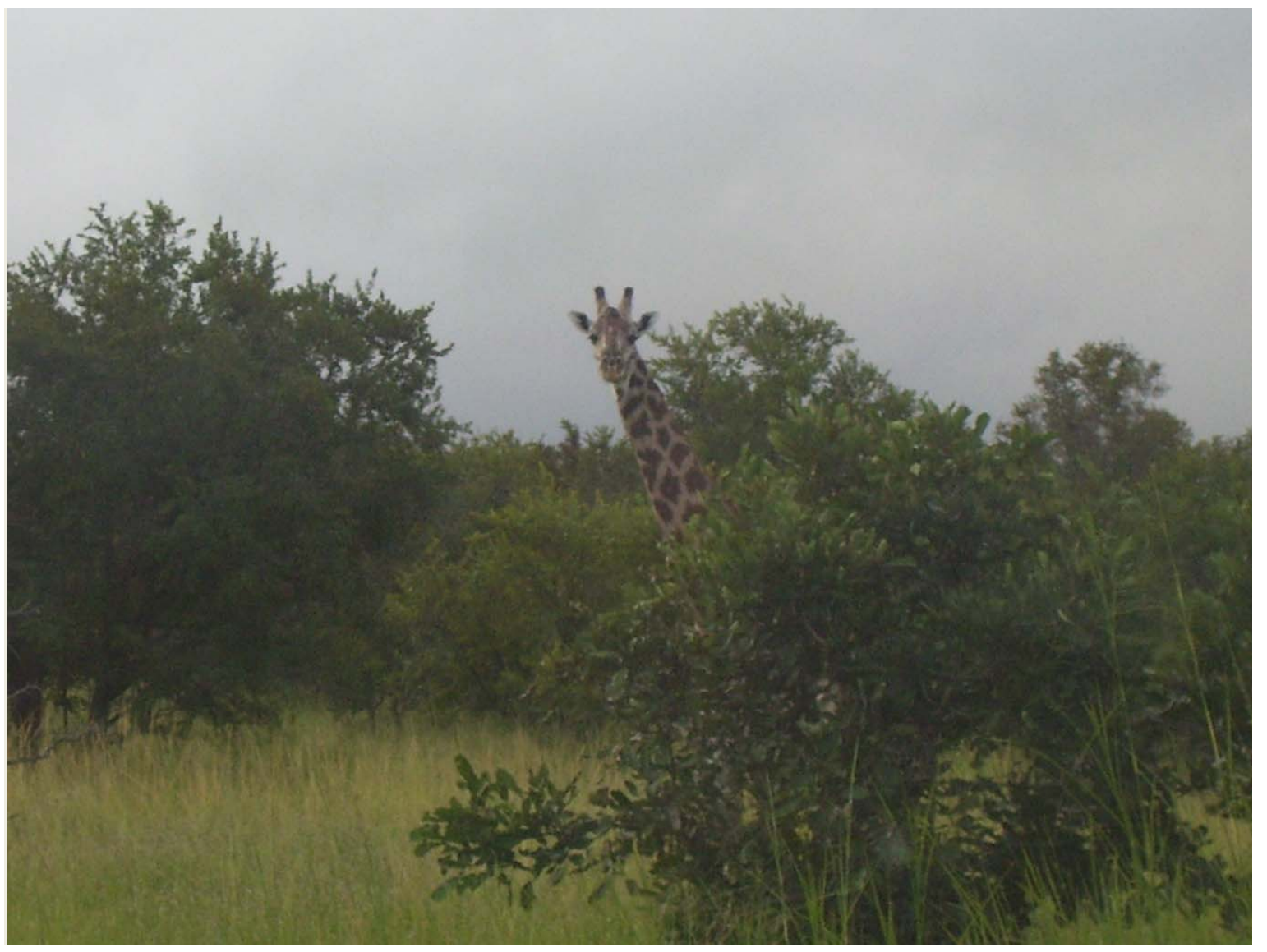

